\section{Increased airway pressure caused by a pentilator}

To the Editor:

We report a progressive increase in airway pressure caused by external pressure on the ventilator relief valve pilot line of the North American Dräger Narkomed $2 \mathrm{C}$ anesthesia machine during anesthesia. Previous check of the anesthesia machine was performed according to the FDA anesthesia apparatus checkout recommendations -1986 .

Twenty minutes after instituting mechanical ventilation in an ASA I parient, the alarms warned of an increased breathing circuit pressure tracing with each ventilation cycle. Visual check showed that an electrical cable was pressing on the ventilator relief valve pilot line (Figure). The breathing circuit pressure pattern reverted to normal after its removal. The design of the same pilot line in the ventilator AV 2 + has been improved by the addition of an internal metal tube.

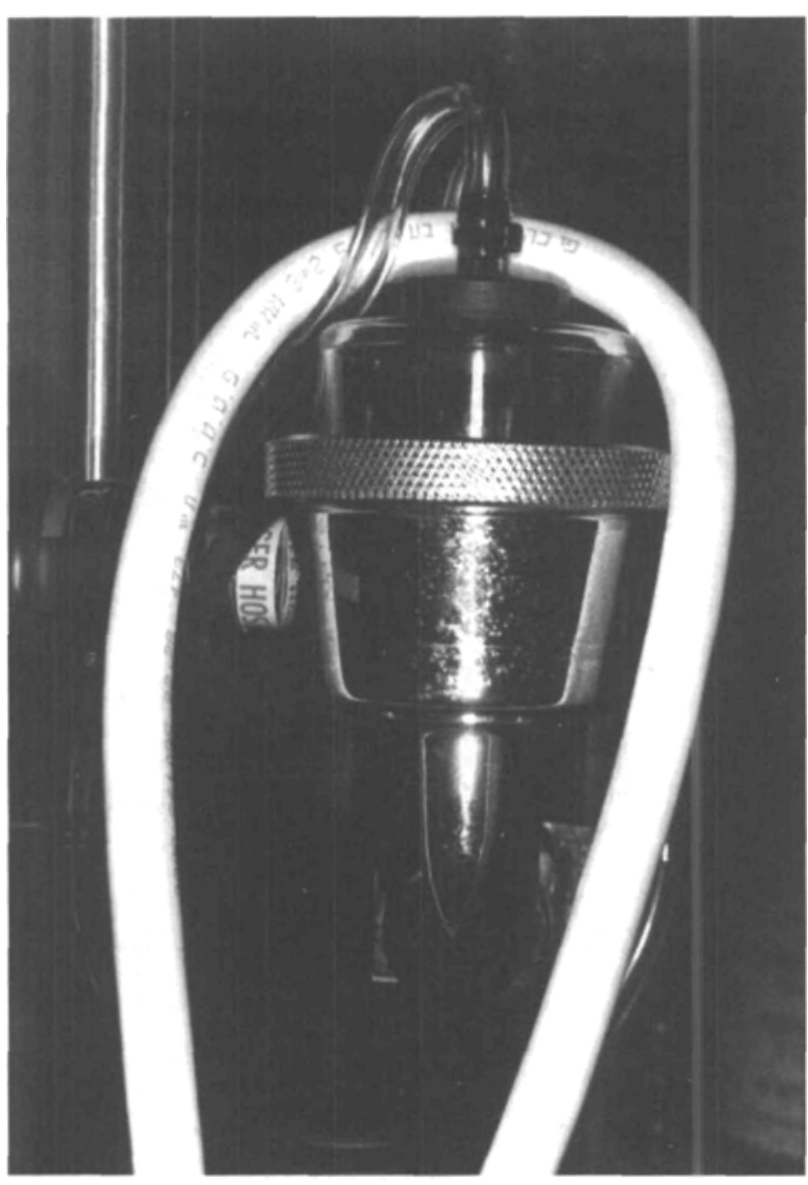

FIGURE Ekectrical cable lying on the ventilator relief valve pilot line
An iatrogenically induced valve malfunction that resulted in increases of the minimum and peak pressures in patient circuit has been described when the connecting tubing from the ventilator was occluded after repositioning the anesthesia machine. ${ }^{1}$ In our case, it seems that an operating room staff' member put the cable on the valve in the middle of the procedure. During the inspiratory phase of ventilation when the pressure of the driving gas in the bellows housing was being transmitted via the pilot tubing to hold the ventilator pressure, the relief valve closed. Kinking of the tubing during this time kept the relief valve closed and prevented gas from leaving the circuit and caused progressive increase in airway pressure.

Luis A. Gaitini MD

Sonia J. Vaida $M D$

Mostafa Somri MD

Geoffrey I. Collins MB

Haifa, Israel

\section{REFERENCE}

1 Eisenkraft JB. Potential for barotrauma or hypoventilation with the Drager AV-E ventilator. J Clin Anesth 1989; 1: 452B6.

\section{Manual pump failure}

To the Editor:

I wish to report an unusual failure of the manual pump of the Y-Type Blood/Solution Set with Pressure Pump, Baxter 2C7613 (Baxter Healthcare Corporation, Deerfield, IL).

An elderly lady presented for abdominal perineal resection. General anesthesia was induced without difficulty. A second large bore intravenous line was established after tracheal intubation and connected to a Hotline $^{\mathrm{TM}}$ (Level I Technologies, Inc., Rockland, MA) to which the Y-Type Blood/Solution Set with Pressure Pump had been attached filled with normal saline as per the manufacturer's instructions. Two litres were infused with free flow and no leakage.

During pelvic dissection, there was an unexpected loss of $750 \mathrm{~mL}$ blood: blood pressure decreased to $90 / 60 \mathrm{mmHg}$ with a heart rate of $110 \mathrm{bpm}$. The intravenous lines were opened wide. The manual pump of the Y-Type Blood/Solution Set was compressed to assist with fluid resuscitation. With the first compression, a jet of fluid squirted from the upper portion of the pressure pump assembly (Figure). The defective Y-Type Blood/Solution Set with Pressure Pump was removed and replaced. 